\title{
Supporting Cross-Border E-commerce of Micro Entrepreneurs in Developing Countries: Export Marketing Strategy
}

\author{
Kihyon Kim ${ }^{1}$, Gyoo Gun Lim ${ }^{2}$ * \\ 1 Business School, Hanyang University, 222 Wangsimni-ro, Seongdong-gu, Seoul, Republic of Korea; kihyon \\ @hanyang.ac.kr \\ * Correspondence: ggseer@gmail.com
}

\begin{abstract}
Cross-border e-commerce is an opportunity for micro, small and medium sized enterprise (MSMEs) in developing countries. Based on a resource-based approach, this research studied how to support resource lacking enterprises with export marketing strategy. It dealt with actual business cases of Mongolian entrepreneurs trying to export Mongolian products to Korean market. Multiple source data including interviews, internal documents, and group discussions, were matched with theories to come up with strategies and validated by supporting organizations in Mongolia and Korea. The research suggests that MSMEs should rely on third party digital platforms rather than setting up their own. For product strtategy of the marketing mix, selecting competitive product categories and supporting them adjusting to foreign markets and quality assurance is needed. For price strategy, locally high-priced products should use a price penetration strategy with a lower price compared to competing foreign products. For place strategy, supporting organizations should partner with exporters for collective delivery. For promotion strategy, they need to support the capacity of MSMEs enabling them to use digital marketing tools effectivly. These strategies were validated and adopted by supporting organizations in Mongolia and Korea.
\end{abstract}

Keywords: Cross border electroniceletronic commerce (CBEC); Export Marketing Strategy (EMS); Marketing Mix; Micro Entrepreneurs; Micro; Small and Medium sized enterprise (MSMEs); Aid for Trade

\section{Introduction}

Cross border electronic commerce (CBEC) is defined as an online channel through which products can be directly sold to consumers via the Internet [25]. By 2022, Businessto-Consumer (B2C) cross-border online sales are expected to account for $22 \%$ of the total e-commerce worldwide [20]. It is growing fast and getting more attention during COVID19.

CBEC has a profound impact on the development of enterprises and the country's progress and in the current international environment [56]. As CBEC reduces trade barriers and promotes trade growth [50]. For developing countries, adapting to e-commerce is just a challenge for entrepreneurs, but it is critical for economic development. It is also critical in poverty reduction, including rural households [33]. It also empowers laborers and raises labor productivityproductiviey [2]. Developing countries are expected to achieve a leapfrog development through CBEC in the long run, although CBEC is concentrated in developed countries in the short term [41].

Firms from emerging e-commerce markets lack opportunities in their domestic markets [3]. So, CBEC is a major revenue opportunity for small and medium-size enterprises [20], The statistics indicated that of the firms that engage solely in CBEC, $82 \%$ are Micro, small and medium enterprises (MSMEs) [50]. Micro enterprise is an entity that retains less than five employees.

There are challenges that MSMEs face. E-commerce is a disruptive technology that entails extensive changes to an organization's routines, business processes, capabilities, 
and culture [14, 60]. Moreover, CBEC contains process of trade, thus it is a complex system, integrating multiple types of service offerings, such as cross-border trade services, electronic payment, logistics services, customs declaration, inspection services, and legal advice services [6]. MSMEs originating in emerging markets, compared to firms in developed markets, are disadvantaged as they have developed within more closed economies that are often shielded from global competition [3]. So, they struggle to understand what to digitalize, which technology to use, and how to implement organizational changes. Also, MSMEs usually have fewer resources available for digitalization [17, 35, 48]. They are managed by a single owner who tends to be a generalist lacking marketing and IT competence $[27,48]$.

So, systematic guidance and support through aid for e-commerce, whch is a publicly funded support unit, is suggested [4]. Aid for e-commerce focuses on equipping developing countries with infrastructure and skills necessary for e-commerce, as a component of aid for trade. It is to address the digital divide and assist developing countries in their trade policy [42]. There are two approaches that aid for e-commerce can be made: external industrial approach and internal firm-level resource- based approach. While external industrial approach deals with external environmental factors at the industrial level, resource-based approach urges a company to develop and utilize resources. Among resources, factors for determining export performance are usually classified into three categories; corporate characteristics, management characteristics and export marketing strategy(EMS),

This paper focuses on the EMS for MSMEs, which is the relationship between variables of marketing and export performance. It includes a company's exporting product, pricing, place, and promotion strategy $[37,19]$. They are called marketing mix, since these strategies regarding 4Ps are mixed organically to create better effects [26]. EMS is a key factor for achieving export performance [10, 30,39]. It is proven to be critical not only for large firms but for MSMEs as well [11, 48]. EMS for MSMEs should be customized. Not only online presence requires a different marketing strategy than off-line [10, 13], marketing for small firms differs from those of large firms [8, 27, 28]. However, EMS remains understudied, despite its great importance for small firms and CBEC [24]. Digital marketing tactics, which is one of EMS, is also under researched [8], although is of great importance for small firms $[17,35]$.

\section{Materials and Methods}

\subsection{Export Marketing Strategy}

EMS is a strategy the firm responds to the interaction of internal and external forces to meet the objectives of the export business. It involves all aspects of marketing mix including product, promotion, pricing and place. Usually, EMS covers product adaptation, communication efficiency, promotion adaptation, distribution support, distributiondistrubution efficiency, and price competitiveness. Usually, standardization decisions to adapt to foreign markets is a key determinant in export performance [10]. For example, firms at the initial exporting stages tend to adopt more standardized export marketing strategies, while those at later stages enjoy more adaptated strategies.

There are prerequisites for EMS. A firm's strategic marketing orientation is also important in marketing strategy [8]. It leads to the adoption of digital technologies, thus positively influencing the performance and competitiveness of an MSME [35]. Most MSMEs lack strategic marketing orientations, because they use most of their resources on production and management. To come up with concrete EMS, a firm needs to decide which digital platform to use. Large companies, equipped with abundant resources and capabilities, can develop and deploy their own digital platforms $[12,14]$. However, MSMEs do not have enough resources to make their own digital platform, in most cases. 
In CBEC, firms are challenged by language barriers, cultural disparities and differences in consumer behaviour $[5,15,52]$. Product is defined as all the benefits through time that the user obtains from the exchange [58]. Product adaptation is defined as the degree to which the firm's product elements are adapted for export markets to accommodate differences in environmental forces, consumer behavior, and competitive situations [30]. For example, regulations governing packaging and labeling can vary significantly among markets. Also, a high degree of product adaptation is needed in a competitive market, due to intense competitive pressures [10]. To differentiate the product in export markets, branding, which entails decisions relating to the name, sign, symbol, design, or a combination of these decision areas, is also needed.

\subsection{Price}

The price is everything given by the acquirer in terms of money, time and effort given to obtain the product [58]. Price should be adjusted to foreign market because economic, political, legal and other environmental forces exist. There are additional costs of export including transportation and legal costs, tariffs, taxes, and other financial trade barriers. Pricing practices of competitors also influence the price. Price adjustment shows a strong positive impact on export performance [21]. Not only price adaptation is necessary, but also competitive pricing is important [34].

\subsection{Place}

Place is defined as everything that is ecessary to smooth the process of exchange (Yudelson 1999), including virtual and intangible aspects of e-commerce. E-commerce has contributed to building relations with customers easily [7]. In the digital context, the purchasing process must be smooth and easy, and it should build relations with customers. For MSMEs, it is difficult to identify and solve supply chain management challenges, which are designed for large enterprises [43]. Distribution channel adaptation to foreign market conditions have an impact on export performance [21].

\subsection{Promotion}

Promotion is all of the information that is transmitted among parties [58]. Promotions includint advertising, sales promotion, personal selling, trade fairs, personal visits, and promotion adaptation, were proven to be effective on export performance [30]. In developing countries, sales promotion, including coupons and samples are effective [9]. In ecommerce, promotion also includes the interactive aspects of digital communication [40]. Digital marketing tactics, such as social media marketing, are positively related to export performance $[11,48]$. So MSMEs need to be aware of the importance of using digital marketing tactics and employ them $[35,48]$.

\subsection{Research Question}

Our Research aims to come up with EMS of CBEC for MSMEs in developing countries, as an aid for e-commerce. This means that publicly funded systems need to support MSMEs resources to strengthen their capacity to enter the foreign markets through e-commerce. So we deal with how to support MSMEs in terms of 4Ps, a marketing mix, as supporting ornanizations. To come up with practical EMS, this research tries to set EMS in a specific context Previous literature on EMS are mainly conceptual, and hardly aligned to actual practice of MSMEs. Those research neglect the peculiar context of MSMEs, and also developing countries, although the underlying logic of those contributions is reasonable in general. Our research tries to bridge the gap between previousprecvious findings as general findings and the peculiar context of MSMEs and devloping countries and come up with practical solutions.

\subsection{Research Framework}


This study deploys EMS as the underpinning framework to combine field data and theory. A multiple case study method was adopted in this research, since a qualitative approach is appropriate for answering the question of how and why (Yin, 2008). We followed commonly accepted standards for conducting case studies in the operations management literature to ensure rigor $[18,47,54]$.

We chose Mongolia MSMEs exporting products to Korea as a case study because of several reasons. First, we could manage to work with MSMEs and supporting organizations in Mongolia and Korea, which enabled the research team to not only study actual business cases, but also to confirm and validate research findings. It means that when we come up with findings after data analysis, we could meet with supporting organizations and consult with those findings to actually implement those strategies. Mongolia based NGO (The Asia Foundation Mongolia Office), Korea based NGO(The Asia Foundation Korea Office), and Korean governmental body(Korea office Korea International Development Agency) established 'Women Business Center(WBC)' in the City of Ulaanbaatar in 2016 to support women micro entreprenereurs. As of 2019, WBC has 3,700 female members and is incubating 47 entrepreneurs. In its first phase between 2016 and 2018, 39 entrepreneurs have completed WBC's incubation programs. The main businesses are hand rafts and service.

Second reason is that Mongolia's e-commerce has improved remarkably over recent years, which makes Mongolia a representative case for developing countries. Of the population of three million, 2.6 million have Internet access, 2 million use smartphones, 1.3 million use SNS on a regular basis [22]. The current Mongolian e-commerce industry has experienced unprecedented growth, with its total revenue increasing over 60 percentages during 2020 [22]. In the capital city of Ulaanbaatar, it has a relatively good infrastructure for e-commerce.

\subsection{Data}

Data was collected via multiple means, including semi-structured interviews, site visits, field observations, internal corporate documents, official public reports, internet resources and focus-group discussions. Multiple sources of data enabled triangulation [18]. For interviews, we employed purposeful sampling and selected 3 companies with the supporting organizations, they are all members of the WBC and located in the WBC building.

Table 1. Overview of interviewees

\begin{tabular}{ccc}
\hline Title 1 & Title 2 & Title 3 \\
\hline Mongolian MSME & Fashion product (Bags) & Owner \\
Mongolian MSMEs & Food product (Beverages) & Owner \\
Mongolian MSMEs & Online buiness & Owner \\
Monoglian NGO & Program management & Staff \\
Monoglian NGO & Program management & Staff \\
Monoglian NGO & Program management & Staff \\
Mongolian Firm & IT, e-commerce, payment & Head of corporate sales \\
Mongolian Firm & Banking, Busienss, payment & Former CEO \\
Mongolian-Korean Associa- & Mongolia-Korea IT incubat- & CEO, Founder \\
tion & ing center & \\
Mongolian-Korean Associa- & Mongolia-Korea IT incubat- & Local staff \\
tion & ing center & Representative \\
Korean NGO & Program management & Staff \\
Korean NGO & Program management & Professor \\
Korean Expert & e-commerce & Student \\
Korean Expert & e-commerce project & Student \\
Korean Expert & e-commerce project &
\end{tabular}




\begin{tabular}{ccc}
\hline Korean Expert & e-commerce project & Student \\
US Expert & e-commerce, MSMEs & Expert \\
\hline
\end{tabular}

For interviews, the research team visited Ullanbaatar, Mongolia. We interviewed the MSME's founder or a staff who is in charge of the CBEC. At each interview, one member from the research team followed a semi structuredsemistructured interview template; the other members and staff from the supporting organization (The Asia Foundation Mongolia Office) raised related questions aimed at exploring incidental findings. The interviews involved questions on topics such as the introductction of the MSMEs, experience of export, familiarization with e-commerce, resource and capacity for CBEC, their current EMS, and their needs for EMS support. Interviewers encouraged free reporting, and there was no forced answer. The interviews were conducted in Mongolian and Korea and the average length was about 1 hour.

We also managed to visit the MSMEs' manufacturing sites and to observe how MSMEs and supporting organizations work, spending approximately 1 hour. We had numerous opportunities to interact informally with the interviewees. We took advantage of the site visits and the informal interactions to learn more about the details of the MSMEs.

With the help of supporting organizations and experienced staffs, we could validate and confirm EMS. Then we organized a focus-group interview with MSMEs and staffts of the WBC to validate EMS. In total, we carried out 15 interviews.

\subsection{Data Analysis}

For data analysisanasysis, we described all MSMEs interview results in CBEC and the research team attempted to identify how informants' understanding and experience of CBEC related to EMS. This analysis is similar to Strauss and Corbin's [46] notion of open coding [23]. The research team repeatedly read the interview transcripts to capture the informants' information regarding EMS. Through discussions, consensus on a set of EMS that represented informants' views was reached [53]. The descriptions were reported back to supporting organizations to ensure correct understanding.

Then we endeavoured to find theoretical interpretations for the finding in the previous step. The research team shifted back and forth between the derived strategiesstragegies and broad scope of literature on EMS to find theories. We made efforts to theoretically support or correct strategies with data from the previous step and come up with strategies. The research transitioned from being inductive to being abductive in that data and existing theory are in tandem [23]. Lastly, focus group discussions were implemented to validate EMS. Hence, Our research tries to come up with realistic EMS based on existing theories and interview findings.

\section{Results}

\subsection{Adopting e-commerce platform}

There are several digital platform options, including to open an independent website or to utilize existing third-party platforms. Third party platforms contain 'large malls' (shopping websites established by distribution companies) and 'open markets' (social commerce). The other option is to use social networking services, such as facebook and instagram, since they have features to help sell products online [32].

MSMEs and supporting organizations want to set up their own independent web platforms and put resources for that. However, they do not have expertise, experience and enough resources to set up and manage digital platforms. So, depite of their plan to pursue independent websiet, most MSMEs stay on the third-party CBEC service platforms. However, according to literature, it is recommeded to use third party platforms since there are positive impacts of using them. MSMEs can lower their asset investment in human resources, training, logistics and warehousing as these supports are provided by 
marketplace platforms. It also helps to build trust and reduce risks and transaction costs [43]. Third party digital platforms optimize trade processes, expand services, make payment easy, coordinate relationships between international logistics providers and warehousing companies, to help MSMEs use the advantage of existing industrial chains [56]. So, it is recommended for MSMEs to rely on third-party digital platforms [3].

Adopting a third party platformplaform has other positive effects in other aspects as well. It facilitates MSMEs' digital transformation through rulemaking. The digital platform provider keeps updating the available services and modifying business rules to meet the changing market situation [55]. Once embedded in and enforced by the digital platform, the business rules prescribe how MSMEs operate. In this way, MSMEs gain a competitive advantage over their competitors.

Table 2. Analysis on e-commerce platforms (Korea)

\begin{tabular}{cccc}
\hline Title 1 & Title 2 & $\begin{array}{c}\text { Business } \\
\text { Registration }\end{array}$ & $\begin{array}{c}\text { E-commerce } \\
\text { Registration }\end{array}$ \\
\hline \multirow{2}{*}{ Independent Website } & Independent Website & $\mathrm{O}$ & $\mathrm{O}$ \\
& Shopping Mall Service & $\mathrm{O}$ & $\mathrm{O}$ \\
\hline \multirow{2}{*}{ Third Party Platform } & Shopping Mall & $\mathrm{O}$ & $\mathrm{O}$ \\
& Open Market & $\mathrm{X}$ & $\mathrm{X}$ \\
\hline Social Networking Service & Business Account & $\mathrm{X}$ & $\mathrm{X}$
\end{tabular}

We analyzed different options for Monolian MSMEs exporting products to Korea. To set up independent web platforms, business registration and e-commerce registration is required. However, using third party platforms and social media does not require both business and e-commerce registration. The third-party platforms such as "G-Market global Shop" provide expanded servicesservicses. Shopping malls are close to select shops managed by the platform, requesting MSMEs qualityquility proven procedures. However, openmarket does not require much information, since it aims to provide services to less-resourced independent sellers. So, considering MSMEs resouce and positive impact of using it, it is desirable to rely on third party platforms, especially open marketsmarets.

So, for supporting organizations such as the Asia Foundation Mongolia Office, partnering with third party platforms, rather than launchinglauching its own digital platform is recommended. As theory recommends, "dual-channel method", which means in its infancy, the executive should expand foreign markets and conduct foreign trade business with a third-party platform and when enterprises acquire enough ability for cross-border e-commerce, they should build their own website to continually improve the operation ability of cross-border e-commerce [56] should be adequate. We suggested this to the Asia Foundation Mongolia office, and they agreed and accepted this.

\subsection{Product Adaptation Strategy}

Mongolian MSMEs try to export to advanced markets nearby, China, Japan and Korea. Key products sold are cashmere, wool, yak, frozen meat, salt, etc. The biggest challenge of Mongolian products in the Korean market are product regulatory environment, market standardsrelupatory of quality, and trust of quality. For example, natural honey products faced difficulty entering the Korean market due to food standards set by Korean honey producers. So, without effort to adapt to the regulatory environment in foreign markets and modify products, it is impossible to export.

Through pressures to meet specific host market requirements, MSMEs can come with innovation $[36,16]$. Product adaptation is not just a prerequisite for export, but it also has positive impacts on export performance [31], product competitiveness and success [21]. Through product adaptation, the exporter acquires customer-orientation, cautiously 
evaluating consumer behavior and market traits. It leads to greater customer satisfaction, which allows greater pricing freedom vis a vis competitor.

After group disccusions with supporting organizations, we come up with specific product adaptation strategies. First, start with choosing a competitive product category. Products with high potentials for competitiveness reflecting Mongolia's unique characteristics need to be selected, such as cashmere and wool. This should be done in a strategic way with market analysis on foreign markets including competitors, legal and regulatory environments in that product category. Then, compose a group of the same product category and make this group as a collective brand, such as 'Mongolian Nature Fashion Initiative'. It can help build quality trust and raise brand awareness. Supporting organizations can actively use the brand power of themselves as "Guarantee of Quality".

\subsection{Price Competitivenes Strategy}

After having interviews with MSMEs, we did SWOT analysis with relevant stakeholders. We found out that most of MSMEs products are not adequate for export, because of the low price compared to logistics expenditures and taxes. For example, hand craft products are not proper for export, considering additional cost added by export compared to its original price. In literatureliteratues, adoption of a price penetration strategy, which is entering the market with lower price and then slowly raising, was positively associated with export performance rather than price skimming strategy, which is starting with high price and reduce it [31].

Table 3. SWOT Analysis (Mongolian produts exporting to Korean market)

\begin{tabular}{|c|c|c|}
\hline & Strength & Weakness \\
\hline Opportunity & 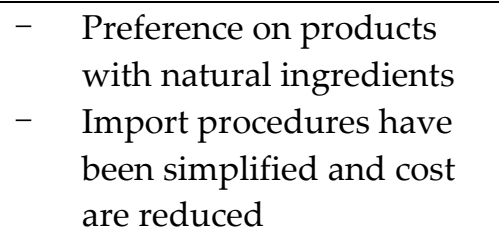 & $\begin{array}{ll}\text { - } & \text { Lack of quality assurance } \\
\text { - } & \text { Low brand awareness }\end{array}$ \\
\hline Weakntess & $\begin{array}{l}\text { - Similar goods from devel- } \\
\text { oping countries }\end{array}$ & 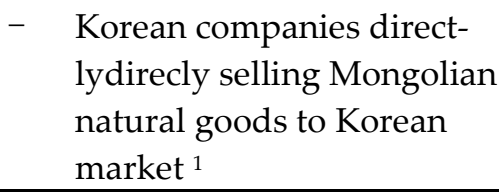 \\
\hline
\end{tabular}

Combining findings from interviews and literature, it should select high price product categories, to cover logistic and relevant costscostgs. After selecting an adequate product category, it needs to adopt a price penetration strategy entering markets with relatively low prices compared to competing brands in foreign markets. For example, cashmere can be chosen, and the price should be adjusted to be lower than competitors.

\subsection{Place Support Strategy}

According to the interview, MSMEs export by themselves even when they do not have relevant experience and knowledge regarding the export process including transportation procedures, tariffs, and legal documentations. Supporting organizations do not include distribution support as their role, making MSMEs dealing distribution individually. In literature, it is recommended to MSMEs to use exporter service by hiring an outsourced service [43]. This makes MSMEs improve service, reduce cost, and focus on the business [30]. Stable business relashionship with exporter support leads to better export performance [10]. Exporters can provide business counseling, market research assistance, sales force training, technical assistance, missionary selling, cooperative advertising, and financing as well [16].

So it is recommended to use exporter service rather than dealing with exporting procedures directly. Also, rather than contracting exporters individually, it is recommeded to 
make partnership contracts as mutiple firmsl, organized by supporting organizations. This is termed as "Collective Delivery". We discussed with supporting organizations to check the validity of the strategy to make partnerships with exporters with multiple firms. We found that there are third-party logistics exporting Mongolian products to Korea, so the strategy can be easily implemented. This is a plausible strategy plausbile and actually implemented in advanced countries. In Korea's case, Korean government agency (Korea trade and investment promotion agency) provides collective delivery services for Korean SME products.

\subsection{Promotion Capacity Strategy}

According to interviews, MSMEs don't have time and resources to plan and implement promotions, because in mostmotst cases they need to keep up with production schedules. Thus, MSMEs have needs of support from outsideouside to plan and implement promotions including design, advertisement and language translations. Previous literature pointed out that technology is becoming less resource-intensive due to the availability of open-source solutions, bringing the adoption and use of digital marketing technologies within the reach of even the smallest firms [35, 39, 49]. It recommends small firms to use small budget marketing tools such as Social Networking Service [17] and search engine advertisements, which allows them to appear at the top of Google search results similar to their larger counterparts [24]. So, for MSMEs, it would be worthwhile to invest in skills and technical knowledge in using digital marketing tactics $[29,49]$. This will help establish processes and routines that can support the burden of limited resources [28].

So, the strategy for MSMEs is to build capacity on digital marketing to make them solve their own needs in an effective and efficient way, rather than relying on external support. After having group discussions, we confirmed that it is a plausible solution to build capacity on digital marketing tools. MSMEs and supporting organizations were both in need of this capacity building, for example, inviting experts to give workshops regarding digital marketing.

\section{Discussion}

Through analyzing multiple sources of data, literature reviews and group discussions, we came up with the following EMS. For adopting digitalditigal platforms, rather than setting up an independent website, MSMEs should use existing third-party digital platforms. This enables them to skip complex legal procedures in foreign countries and also use expanded services of the platrom. For product adaptation strategy, product categories with competitiveness should be selective and be adjusted to foreign legal and regulatory environments. Then product categoty can be collectively branded to ensure quality and raise awareness using trust of supporting organizations. For price competitiveness strategy, high price product categories should be selected to cover export-related costs. Then price penetration strategy should be implemented with entering foreign markets with lower prices compared to competitors. For place support strategy, partnering with exporters and using collective delivery for multiple MSMEs would be strategic, rather than export individually or contracting individually. It would reduce cost and make MSMEs focus on their own business. For promotion capacity strategy, MSMEs need to make use of less resourceresouce consuming digital marketing tools, such as SNS, and supporting organizations need to support this with capacity building programs.

\section{Conclusions}

For theoretical implication, this research tried to bridge the gap between theoretical research findings and application on business cases of MSMEs in developing countries. Merging findings from both interviews and literature, and then combining them to EMSs which were agreed and confirmed by group discussion with MSMEs and supporting organizations in both Mongolia and Korea, this research suggestd EMS in all 4P marketing 
mix and digital plaform addption. Based on a resource-based approach, this study has an implication on application of EMS on under-researched groups of MSMEs in developing countries. As previously pointed out, EMS in MSMEs and also in developing countries should be different from large companies in developed countries. As a case study, this can give an example of applying theoretical findings in a specific context.

Secondly, relying on multiple source data, this study tried to develop a case study method with practical conclusions which is meaningful both in theory and cases. EMS suggested by this study actually applied to supporting organizations. This confirmse its validity of findings.

As managerial implications, to support emerging economies, it is important to support MSMEs to do e-commerce, since it is a new source of economic growth. Supporting organizations, such as international donors, donor countries and relevant organizations need to support export marketing strategies. Not just external factors such as legal and policy environments, firm-level resources should be supported. Supporting organisationsorganitions need to broaden the perspective and scope of their work to resourceresouce of MSMEs and market challenge they are facing. To narrow the gap between MSMEs face and their resources, supporting organizations should actively working with partners. Supporting organizations can directly work with e-commerce platforms, 3rd party logistics and local marketing agencies. LastlyLastlyl, supporting organizations should work closely with entrepreneurs, so that the support can be effective and sustainable. Capacity development for entrepreneursentreprenerus and needs assessment of their entrepreneurial activities should be the starting point of aid for e-commerce.

There are several limitations of this study. First, our examination of SME digital transformation was conducted in the unique economic context of Mongolia and Korea. Also, Data has been collected from the only capital city of Mongolia, which may not represent the whole country's population. Thus, Our findings might be unique to the particular social and economic development stage of Mongolia and specific groups in its capital. Future studies are highly recommended to select a more diversified group of entrepreneurs, such as rural producers. Secondly, we relied on interviews with a relatively small number of informants. Moreover, most of the informants in this study were either entrepreneurs or staff, who are on the supplier side, not consumers. Even though we tried to enhance interview data with direct observations and informal conversations, we were unable to formally triangulate what an informant answered. Third, We only focused on marketing strategy, based on resourceresouce based theory and we did not deal with external environments such as legal and policypolici level support.

Future research is needed to confirm each export marketing strategies with quantitativeQuatitative research. This section is not mandatory but can be added to the manuscript if the discussion is unusually long or complex.

Author Contributions: Conceptualization, K.K.; methodology, K.K.; validation, K.K. and G.L.; formal analysis, K.K.; investigation, K.K. and G.L.; resources, K.K. and G.L.; data curation, K.K. and G.L.; writing - original draft preparation, K.K.; writing - review and editing, K.K.; visualization, K.K.; supervision, G.L.; project administration, K.K.; funding acquisition, K.K. and G.L. All authors have read and agreed to the published version of the manuscript.

Funding: This research was funded by The Asia Foundation Korea Office.

Acknowledgments: In this section, you can acknowledge any support given which is not covered by the author contribution or funding sections. This may include administrative and technical support, or donations in kind (e.g., materials used for experiments).

Conflicts of Interest: The authors declare no conflict of interest.

\section{References}


1. Aaby, Nils-Erik, and Stanley F. Slater. "Management influences on export performance: a review of the empirical literature 1978-1988." International marketing review, 1989.

2. Atrostic, B. K., \& Nguyen, S. V. IT and productivity in US manufacturing: do computer networks matter?. Economic Inquiry, 2005, 43(3), 493-506.

3. Banerjee, P. K., \& Ma, L. C. Routinisation of B2B E-commerce by small firms: A process perspective. Information Systems Frontiers, 2012, 14(5), 1033-1046.

4. Barann, B., Hermann, A., Cordes, A. K., Chasin, F., \& Becker, J. (2019, January). Supporting digital transformation in small and medium-sized enterprises: a procedure model involving publicly funded support units. In Proceedings of the 52nd Hawaii International Conference on System Sciences.Bartikowski, B., \& Singh, N. Should all firms adapt websites to international audiences? Journal of Business Research, 2014, 67(3), 246-252.

5. Baruca, A., \& Zolfagharian, M. Cross-border shopping: Mexican shoppers in the US and American shoppers in Mexico. International Journal of consumer studies, 2013, 37(4), 360-366.

6. Bartikowski, B., \& Singh, N. Should all firms adapt websites to international audiences? Journal of Business Research, 2014, 67(3), 246-252.

7. Bhatt, G. D., \& Emdad, A. F. An analysis of the virtual value chain in electronic commerce. Logistics Information Management. 2001

8. Bocconcelli, R., Cioppi, M., Fortezza, F., Francioni, B., Pagano, A., Savelli, E., \& Splendiani, S. SMEs and marketing: a systematic literature review. International Journal of Management Reviews, 2018, 20(2), 227-254.

9. Cateora, P., \& Graham, J. L. International Marketing, PrenticePrentince Hall Inc. International Edition. 1999.

10. Cavusgil, S. T., \& Zou, S. Marketing strategy-performance relationship: an investigation of the empirical link in export market ventures. Journal of marketing, 1994, 58(1), 1-21.

11. Chaffey, D., \& Ellis-Chadwick, F. Digital marketing. Pearson uk. 2019.

12. Chen, J. E., Pan, S. L., \& Ouyang, T. H. Routine reconfiguration in traditional companies'e-commerce strategy implementation: A trajectory perspective. Information \& Management, 2014, 51(2), 270-282.

13. Colton, D. A., Roth, M. S., \& Bearden, W. O. Drivers of international e-tail performance: the complexities of orientations and resources. Journal of International Marketing, 2010, 18(1), 1-22.

14. Cui, M., \& Pan, S. L. Developing focal capabilities for e-commerce adoption: A resource orchestration perspective. Information $\mathcal{E}$ Management, 2015, 52(2), 200-209.

15. Cyr, D. Modeling web site design across cultures: relationships to trust, satisfaction, and e-loyalty. Journal of management information systems, 2008, 24(4), 47-72.

16. Czinkota, M. R., \& Ronkainen, I. A. International Marketing". The Dryden Press, New York. 1998.

17. Eggers, F., Hatak, I., Kraus, S., \& Niemand, T. Technologies that support marketing and market development in SMEs - Evidence from social networks. Journal of Small Business Management, 2017, 55(2), 270-302.

18. Eisenhardt, K. M. Building theories from case study research. Academy of management review, 1989, 14(4), 532-550.

19. Ford, I. D., \& Leonidou, L. C. ResearchResearcb Developments in International Marketing. New Perspectives on International Marketing, 3-32. 1991.

20. Forrester Research, 2019.

21. Fuchs, M., \& Köstner, M. Antecedents and consequences of firm's export marketing strategy: An empirical study of Austrian SMEs (a contingency perspective). Management Research Review. 2016

22. Gantulga, U., Sampil, B., \& Davaatseren, A. Analysis of E-Commerce Adoption in Ulaanbaatar, Mongolia. Research on Trade (Korea ed.), 2021, 17, 67-80.

23. Gioia, D. A., Corley, K. G., \& Hamilton, A. L. Seeking qualitative rigor in inductive research: Notes on the Gioia methodology. Organizational research methods, 2013, 16(1), 15-31. 
24. Goldman, S., van Herk, H., Verhagen, T., \& Weltevreden, J. (2020). VU Research Portal.

25. Gomez-Herrera, E., Martens, B., \& Turlea, G. The drivers and impediments for cross-border e-commerce in the EU. Information Economics and Policy, 2014, 28, 83-96.

26. Jang Sang-sik, Nam Kyung-du, \& Park Kwang-seo. A study on the expansion of overseas direct sales by exploring factors of purchasing overseas consumers. Trade Research, 2016, 12(5), 291-308.

27. Jones, R., \& Rowley, J. Entrepreneurial marketing in small businesses: A conceptual exploration. International small business journal, 2011, 29(1), 25-36.

28. Kraus, D., Reibenspiess, V., \& Eckhardt, A. How voice can change customer satisfaction: a comparative analysis between ecommerce and voice commerce. 2019

29. Lam, W., \& Harker, M. J. Marketing and entrepreneurship: An integrated view from the entrepreneur's perspective. International small business journal, 2015, 33(3), 321-348.

30. Leonidou, L. C., Katsikeas, C. S., \& Samiee, S. Marketing strategy determinants of export performance: a meta-analysis. Journal of Business research, 2002, 55(1), 51-67.

31. Lestari, D. Measuring e-commerce adoption behaviour among gen-Z in Jakarta, Indonesia. Economic Analysis and Policy, 2019, 64, 103-115.

32. Lin, H., Li, R., Hou, S., \& Li, W. Influencing factors and empowering mechanism of participation in e-commerce: An empirical analysis on poor households from Inner Mongolia, China. Alexandria Engineering Journal, 2021, 60(1), 95-105.

33. Louter, P. J., Ouwerkerk, C., \& Bakker, B. A. An inquiry into successful exporting. European Journal of Marketing, 1991, 25(6), 723.

34. Mazzarol, T. SMEs engagement with e-commerce, e-business and e-marketing. Small enterprise research, 2015, 22(1), 79-90.

35. McGuinness, N. W., \& Little, B. The influence of product characteristics on the export performance of new industrial products. Journal of Marketing, 1981, 45(2), 110-122.

36. Miesenbock, K. J. Small businesses and exporting: a literature review. International Small Business Journal, 1988, 6(2), 42-61.

37. Mongol bank 2020

38. Morgan, E. J., Naudé, P., \& Baxter, A. Assessing the adoption of business-to-business E-commerce: a judgemental modelling approach. In Industrial Marketing and Purchasing Conference.002). 2002.

39. Morris, M., \& Ogan, C. The Internet as mass medium. Journal of Computer-Mediated Communication, 1996, 1(4), JCMC141.

40. Panagariya, A. Preferential trade liberalization: the traditional theory and new developments. Journal of Economic literature, 2000, 38(2), 287-331.

41. paragraph 3 of Article 21 of the TFA)

42. Qi, X., Chan, J. H., Hu, J., \& Li, Y. Motivations for selecting cross-border e-commerce as a foreign market entry mode. Industrial Marketing Management, 2020, 89, 50-60.

43. Soinio, J., Tanskanen, K., \& Finne, M. How logistics-service providers can develop value-added services for SMEs: a dyadic perspective. The International Journal of Logistics Management. 2012.

44. Sousa, R., Yeung, A. C., \& Cheng, T. C. E. Customer heterogeneity in operational e-service design attributes: an empirical investigation of service quality. International Journal of Operations \& Production Management. 2008.

45. Still, R. R., \& Hill, J. S. Adapting consumer products to lesser-developed markets. Journal of Business Research, 1984, 12(1), 5161.

46. Strauss, A., \& Corbin, J. Basics of qualitative research techniques (pp. 1-312). Thousand oaks, CA: Sage publications. 1998.

47. Stuart, I., McCutcheon, D., Handfield, R., McLachlin, R., \& Samson, D. Effective case research in operations management: a process perspective. Journal of operations management, 2002, 20(5), 419-433.

48. Taiminen, H. M., \& Karjaluoto, H. The usage of digital marketing channels in SMEs. Journal of Small Business and Enterprise Development. 2015. 
49. Tavengerwei, R. Using trade facilitation to assist MSMEs in E-commerce in developing countries. Journal of International Economic Law, 2018, 21(2), 349-378.

50. Terzi, N. The impact of e-commerce on international trade and employment. In Encyclopedia of E-Commerce Development, Implementation, and Management (pp. 2271-2287). IGI Global. 2016.

51. UNCTAD's B2C consumer index

52. Usunier, J. C., Van Herk, H., \& Lee, J. A. International and cross-cultural business research. Sage. 2017.

53. Van Maanen, J. Reclaiming qualitative methods for organizational research: A preface. Administrative science quarterly, 1979. 24(4), 520-526.

54. Voss, C., Tsikriktsis, N., \& Frohlich, M. Case research in operations management. International journal of operations $\mathcal{E}$ production management. 2002.

55. Volkoff, O., Strong, D. M., \& Elmes, M. B. (2007). Technological embeddedness and organizational change. Organization science, 18(5), 832-848.

56. Yang, J., Yang, N., \& Yang, L. The Factors Affecting Cross-border E-commerce Development of SMEs-An Empirical Study. In WHICEB (p. 12). 2014, June.

57. Yin, L. X. The history and evolution of e-commerce. 2008. Retrieved April, 6, 2017.

58. Yudelson, J.. Adapting McCarthy's four P's for the twenty-first century. Journal of Marketing Education, 1999. $21(1), 60-67$.

59. Zeng, D., Wang, F. Y., Zheng, X., Yuan, Y., Chen, G., \& Chen, J.. Intelligent-commerce research in China. IEEE Intelligent Systems, 2008, 23(6), 14-18.

60. Zou, S., \& Stan, S. The determinants of export performance: a review of the empirical literature between 1987 and 1997. International marketing review. 1998.

61. Dominici, G. From marketing mix to e-marketing mix: a literature overview and classification. International journal of business and management, 2009, 4(9), 17-24.

62. Allen, E., \& Fjermestad, J. E-commerce marketing strategies: an integrated framework and case analysis. Logistics information management. 2001 